\title{
Analysis on the Commercial Grade Items Dedication of Emergency Diesel Generator Set Level Transmitter
}

\author{
Jingyuan Yang, Chenggang Yang*, Dongao Han, Zilong Yi, Jiaqi Huang \\ Nuclear and Radiation Safety Centre MEE, Beijing 102400, China
}

\begin{abstract}
Commercial grade items dedication provides an in-depth analysis of key characteristics of commercial grade items. Technical acceptance of commercial grade items dedication is targeted. Commercial grade items dedication can improve the quality control level of nuclear power plant equipment and effectively compensate for the deficiencies in the process control and quality uncertainties. This article sorts out the differences between ISO9001 and HAF003 and RCC-E requirements, and analyzes the document system, work process, key characteristics, acceptance methods and evaluation process of the commercial grade items dedication of the emergency diesel generator set liquid level transmitter.
\end{abstract}

\section{Introduction}

Commercial grade items dedication originated in the United States. In the 1980s, US nuclear power orders began to decline sharply, and a large number of equipment suppliers abandoned the quality assurance system that complies with 10CFR50 Appendix B. The reduction in equipment purchases and the number of suppliers has resulted in high procurement costs, forcing more and more equipment purchasers to purchase alternatives from alternative suppliers, which often do not establish compliance with 10 CFR 50 Appendix B. The required quality assurance system. Under this circumstance, the US nuclear industry has explored the commercial grade items dedication approach and has conducted a series of studies on how to determine that these commercial grade items can reliably perform their safety functions.

The National Nuclear Security Administration has licensed some large nuclear safety equipment and does not require nuclear safety components. Failure of these components can result in loss of functionality of the plant and a significant impact on the operational safety of the nuclear facility. The emergency diesel generator set belongs to the category of Civil Nuclear Safety Equipment Catalogue (First Batch). The suppliers of safety grade components such as pumps, valves, motors and sensors contained in the system belong to the sub-suppliers of the complete set of suppliers and are not strictly included. Licensing or registration supervision work. The evaluation of commercial grade items on these devices can effectively prevent the quality risks in the manufacturing process of commercial grade items and improve the quality of equipment. In this paper, the document system of commodity grade item evaluation of emergency diesel generator set FMI51 liquid level transmitter is sorted out, the workflow of commodity grade item dedication is introduced, the key characteristics of equipment are analyzed, and the FMI51 type liquid level transmission is analyzed. The determination of the acceptance method for commodity grade assessment was discussed. ${ }^{[1-4]}$

\section{Commercial Grade Items Dedication Document System}

At present, the supply performance, personnel qualifications, venues, quality assurance systems, of safety-grade component suppliers, are also in the gray area of nuclear safety equipment supervision. China's current regulatory concept with the license system as the core does not take into account the procurement of commercial grade items. There is no relevant content of commercial grade items in HAF003 and the regulations on the supervision and administration of civil nuclear safety equipment. Therefore, it should be based on the quality assurance points of equipment suppliers in the nuclear safety regulations, the regulatory requirements of the National Nuclear Safety Administration for emergency diesel generator sets and components, and the quality control process management requirements for nuclear equipment ${ }^{[1]}$. The relevant technical documents were evaluated to form a document system for the evaluation of commodity grade items of the emergency diesel generator set FMI51 liquid level transmitter, as shown in Table 1.

\footnotetext{
* Corresponding author: yangchenggang@chinansc.cn
} 
Table 1 FMI51 liquid level transmitter commodity grade item assessment document system

\begin{tabular}{|l|l|}
\hline Types & Content \\
\hline Regulation & $\begin{array}{l}\text { Regulations on Supervision and Administration of Civil Nuclear Safety } \\
\text { Equipment, Regulations on Supervision and Administration of Imported Civil } \\
\text { Nuclear Safety Equipment, Safety Regulations for Quality Assurance of Nuclear } \\
\text { Power Plants, Relevant Management Documents for Import Safety Inspection of } \\
\text { Nuclear Safety Equipment, and Emergency Diesel Power Generation Issued by } \\
\text { the National Nuclear Safety Administration Management requirements related to } \\
\text { unit supervision }\end{array}$ \\
\hline $\begin{array}{l}\text { US commodity grade item } \\
\text { assessment technical document }\end{array}$ & $\begin{array}{l}\text { 10CFR21, 10CFR50 Appendix B, R.G.1.152, Generic Letter 89-02, 91-05, IP } \\
\text { 43004, IP88114 }\end{array}$ \\
\hline Standard & IEEE 387, IEEE 323, RCC-E, KTA3505, KTA3702 \\
\hline Supplier evaluation document & $\begin{array}{l}\text { Supplier quality management system, equipment operation performance, } \\
\text { equipment manufacturing quality control outline }\end{array}$ \\
\hline Technical assessment document & $\begin{array}{l}\text { Procurement technical requirements, equipment instruction manual, drawings, } \\
\text { equipment completion report }\end{array}$ \\
\hline Assessment document & $\begin{array}{l}\text { Commodity-level item evaluation outline and procedures, equipment key } \\
\text { characteristics analysis report, commodity-level item acceptance procedure }\end{array}$ \\
\hline
\end{tabular}

7. Traceability of items: Emphasize the uniqueness

\section{Analysis of the difference between ISO9001, HAF003 and RCC-E requirements}

SQS has approved the management system of the liquid level transmitter company, which meets the requirements of ISO9001 (2015), ISO14001 (2015) and OHSAS18001 (2007) standards. The company's quality management system has obtained ISO9001 system certification, but it does not hold the registration confirmation of China's imported nuclear safety equipment and has not established a corresponding quality assurance system. Through combing, compared with ISO9001, HAF003 and RCC-E have stricter quality management system requirements, which are mainly reflected in:

1. Document control: To communicate the main information through documents, a general outline and sub-outline of each type of work must be established, and there must be written document requirements for activities that affect quality. Before the document is released, it should be confirmed by someone other than the author of the document.

2. Hierarchical management: According to the importance of safety, the method or level of control and verification shall be adjusted accordingly.

3. Document changes: The changed documents must be reviewed and approved by the same unit reviewing and approving the original documents or another unit specifically designated by them.

4. Design changes: It is emphasized that design changes must adopt the same design control measures as the original design, and must be reviewed and approved by the same team or unit reviewing and approving the original design documents.

5. Design verification: Design verification must be carried out by personnel or groups not participating in the original design. The verification method must be determined by the design unit, and the verification results must be documented within the specified scope.

6. External audit: Emphasize the necessity and scope of external audit. and traceability of identification.

8. Record system: Clearly stipulate the storage, custody and processing of records.

9. The organization has clear rights and responsibilities: It is clear that the interface relationship should be established, and it is clear that the person who is mainly responsible for the quality is the undertaker of the work, not the person who verifies the quality. It is clear that the personnel and departments who is mainly responsible for the quality assurance function should have sufficient organizational independence and should not be constrained by funds and schedule.

10. The procurement process has clear requirements: There are operational requirements for the scope of work, technical requirements, source inspection, service assurance, non-conformance handling, sub-supplier management, etc., and the requirements should be transmitted to each level of suppliers in the subcontracting chain.

11. Product identification and traceability: The documents required by the contract to be delivered to or available to the customer should be identified, and the relationship with the related products should be clarified.

12. Supervision and measurement of products: The verification, confirmation, supervision, testing and specific inspection activities required by the contract for the implementation of the product (proposed by this rules or the purchase order) should be performed by personnel different from the original verification activities.

13. Strict control of non-conforming products: There are clear requirements on the handling authority, working procedures, reporting system, and documentation of non-conforming products, etc.

Commodity-level evaluation of items should be evaluated from two aspects: the quality management system and the item quality itself. Generally speaking, compared with the nuclear quality assurance system, the quality management system of the item supplier who evaluate the commodity-level item assessment is far behind. Therefore, in the evaluation process of commodity-level items, the above-mentioned quality system evaluation criteria should be fully considered, and 
the key characteristics and acceptance methods should be reasonably selected.

\section{Commercial Grade Items Dedication Workflow}

The evaluation of commercial grade items is mainly through technical evaluation and acceptance assessment to confirm that the quality of the items can meet the requirements of relevant laws and standards and meet the requirements for on-site use. Items evaluated by commercial grade items are designed to meet the design control and procurement control requirements of functions, performance, dimensions, materials, interfaces, specified in the procurement documents [5]. The evaluation content mainly includes item identification, safety function confirmation, key characteristic confirmation, acceptance method determination, acceptance activity implementation, and record of acceptance activity results. Acceptance methods mainly include specific tests and inspections, commercial-level investigations, source verification and quality record inspections ${ }^{[6]}$

\subsection{Item Identification}

The liquid level transmitter is not designed for nuclear power plants. Because it was previously used as a component of the complete equipment, it was delivered and used with the emergency diesel generator set. The liquid level transmitter was not designed and manufactured according to the nuclear grade special standards, specifications and quality assurance requirements. There are mature applications in other industries that can be purchased directly according to the product descriptions published by the manufacturer.

\subsection{Security Function Confirmation}

The identification of safety functions is the basis for the selection of key features. The liquid level transmitter uses the capacitance principle to measure the liquid level value of the emergency diesel engine lubricating oil. The normal liquid level value of the lubricating oil storage tank is $140 \mathrm{~mm} \sim 225 \mathrm{~mm}$; after the earthquake accident, the liquid level value of the lubricating oil still needs to be correctly measured. The item has only one safety function and is a nuclear safety anti-seismic Class I device.

\subsection{Key Characteristics Confirmation}

Validation of key characteristics includes determining the key characteristics of the equipment that evaluates all parts, materials, and preset safety features of the item. Common key features include identification, physical, performance, and reliability characteristics, as shown in Table 2.

Table 2 General Key Characteristics

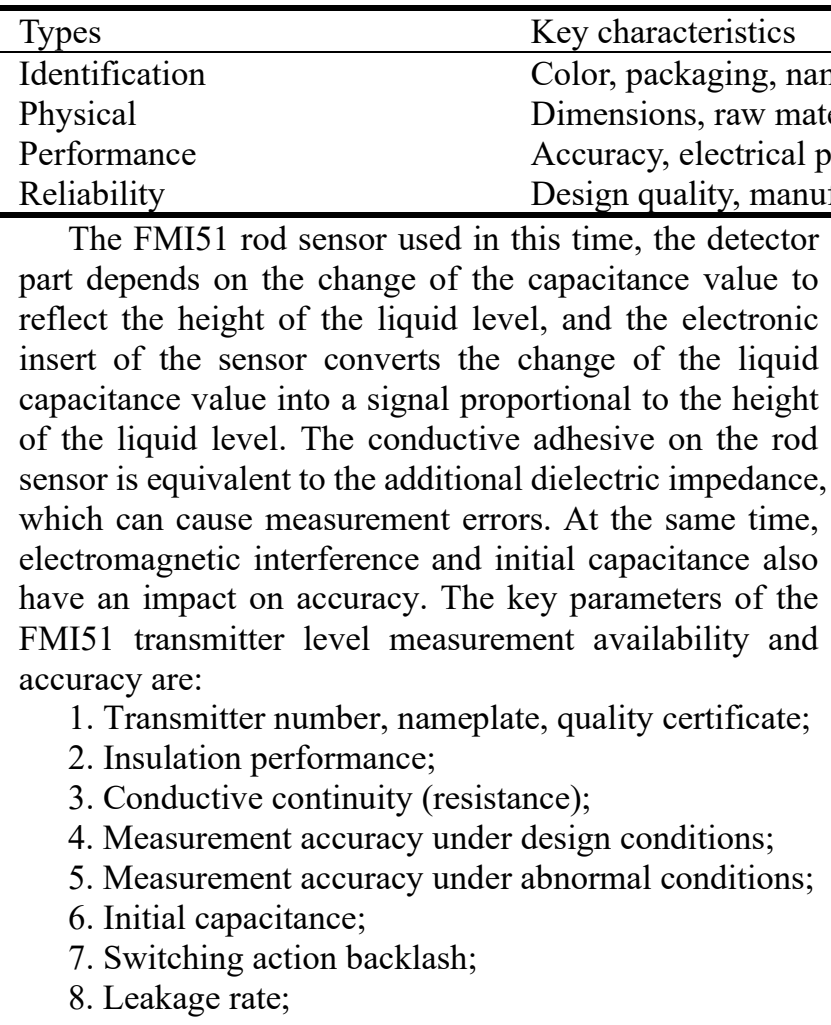

\subsection{Acceptance method is determined}

\subsubsection{Specific test and inspection}

Because the device performs security functions, specific tests are required to verify the key features of the device, 
including the device's own functional performance, long-term operating environment impact, and abnormal environmental impact. This batch of liquid level transmitters has only one model, 2 samples are taken for special test and inspection. The test items and test conditions are shown in Table 3. Physical test sample shown in Figure 1

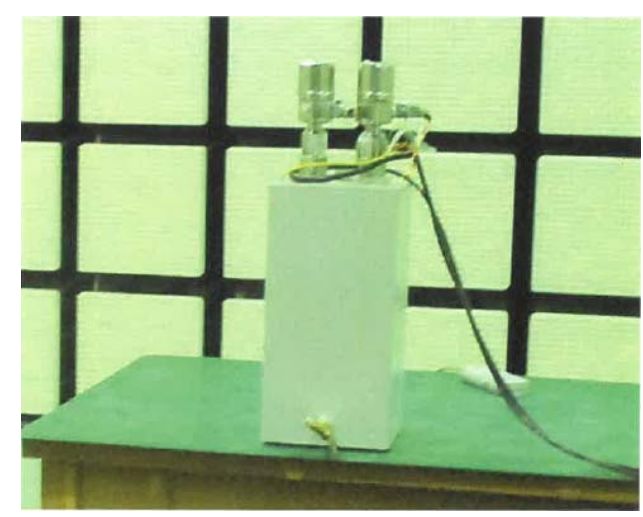

Figure 1 Physical test sample

Table 3 Specific test items and test conditions for product-level item evaluation

\begin{tabular}{|c|c|c|}
\hline test items & test conditions & $\begin{array}{l}\text { The } \\
\text { standard/regulation } \\
\text { based on }\end{array}$ \\
\hline Appearance inspection & Visual inspection, hand feeling & JB/T9261 \\
\hline Dielectric strength test & $500 \mathrm{VAC}, 50 \mathrm{~Hz}, 60 \mathrm{~s}$ & RCC-E MC3120 \\
\hline Insulation resistance measurement & $500 \mathrm{VDC}$, Stable indication for more than $10 \mathrm{~s}$ & RCC-E MC3230 \\
\hline $\begin{array}{l}\text { Basic error, hysteresis and repeatability err } \\
\text { or }\end{array}$ & $\begin{array}{l}\text { Apply } 0 \%, 25 \%, 50 \%, 75 \% \text { and } 100 \% \text { range } \\
\text { input signals in sequence to measure the output } \\
\text { signal error corresponding to the positive and } \\
\text { negative strokes }\end{array}$ & \\
\hline Start-up drift & $\begin{array}{l}\text { Apply the input signal of } 10 \% \text { range first, and } \\
\text { record the output signal at } 5 \mathrm{~min}, 1 \mathrm{~h} \text { and } 4 \mathrm{~h} \\
\text { after power-on; disconnect the power supply, } \\
\text { leave it for a period of time (about } 24 \mathrm{~h} \text { ), and } \\
\text { then repeat the test with the input signal of } 90 \% \\
\text { range }\end{array}$ & \\
\hline Output load change test & $\begin{array}{l}\text { When inputting the signal } 10 \%, 50 \% \text { and } 90 \% \\
\text { to the level gauge in sequence, adjust the load } \\
\text { resistance of the level gauge to increase from } \\
0 \Omega \text { to } 400 \Omega\end{array}$ & \\
\hline Main power change test & $\begin{array}{l}\text { The instrument voltage changes within the } \\
\text { range of }-20 \% \text { to }+30 \% \text { of its rated voltage }\end{array}$ & \\
\hline Power reverse protection & $\begin{array}{l}\text { Apply the maximum supply voltage in reverse } \\
\text { and continue for } 1 \mathrm{~min}\end{array}$ & \\
\hline $\begin{array}{l}\text { EMC (Electromagnetic Compatibility) test: } \\
\text { - } \text { RS(Radiated Susceptibility) test; } \\
\text { - } \text { CS(Conducted Susceptibility) test; } \\
\text { - PFMF(Power frequency magnetic fiel } \\
\text { d) immunity test; } \\
\text { PMF(Pulse Magnetic Field) immunity } \\
\text { test; } \\
\text { - Surge Immunity Test; } \\
\text { EFT/B(Electrical Fast Transient/ Brust) } \\
\text { Immunity Test; } \\
\text { ESD(Electrostatic Discharge) Immunity } \\
\text { Test }\end{array}$ & $\begin{array}{l}\text { Level 3: } 10 \mathrm{~V} / \mathrm{m} \\
\text { Level 4: } 30 \mathrm{~A} / \mathrm{m} \\
\text { Level 4: } 300 \mathrm{~A} / \mathrm{m} \\
\text { Level 3: Differential mode } 1 \mathrm{KV} \\
\text { Contact discharge: } \pm 4 \mathrm{kV} \\
\text { Air discharge: } \pm 8 \mathrm{kV}\end{array}$ & GB/T17626.2-2006 \\
\hline $\begin{array}{l}\text { Environmental temperature (and voltage) in } \\
\text { fluence test }\end{array}$ & $\begin{array}{l}\text { Keep it on a temperature platform of } 0^{\circ} \mathrm{C} \text { and } \\
55^{\circ} \mathrm{C} \text { for } 3 \mathrm{~h} \text {, and apply input signal of } 25 \% \text {, } \\
50 \%, 75 \% \text { range }\end{array}$ & RCC-EMC4700 \\
\hline Free drop test & Drop height $280 \mathrm{~mm}, 4$ drops & GB/T2423.8-2008 \\
\hline
\end{tabular}




\begin{tabular}{|c|c|c|}
\hline $\begin{array}{l}\text { High temperature test } \\
\text { Low temperature test } \\
\text { Rapid temperature change test } \\
\text { Cyclic damp heat test }\end{array}$ & \begin{tabular}{|l|}
$70^{\circ} \mathrm{C}, 96 \mathrm{~h}$ \\
$-25^{\circ} \mathrm{C}, 96 \mathrm{~h}$ \\
$-25^{\circ} \mathrm{C}, 70^{\circ} \mathrm{C}, 5$ cycles \\
$25^{\circ} \mathrm{C} \sim 55^{\circ} \mathrm{C}, 95 \% \mathrm{RH} ; 2$ cyclic damp heat tests, \\
$24 \mathrm{~h}$ each cycle, $48 \mathrm{~h}$ in total \\
\end{tabular} & $\begin{array}{l}\text { GB/T2423.2-2008 } \\
\text { IEC60068-2-2: } 2007 \\
\text { EJ/T1197 }\end{array}$ \\
\hline Running aging test & $\begin{array}{l}\text { Under the condition of maximum voltage and } \\
\text { maximum load, } \\
55^{\circ} \mathrm{C}, 360 \mathrm{~h} ; 40^{\circ} \mathrm{C}, 360 \mathrm{~h}, 720 \mathrm{~h} \text { in total }\end{array}$ & $\begin{array}{l}\text { GB/T2423.2-2008 } \\
\text { EJ/T1197-2007 }\end{array}$ \\
\hline Vibration aging test & $10 \mathrm{~Hz} \sim 2000 \mathrm{~Hz}, 2 \mathrm{~h}$ in each direction & GB/T2423.10-2008 \\
\hline Seismic test & $\begin{array}{l}\text { Three-axis seismic station, } 2 \text { times } 0 \mathrm{~m} \text { floor } \\
\text { response spectrum, peak acceleration }>2 \mathrm{~g}\end{array}$ & $\begin{array}{l}\text { HAF.J0053-1995 } \\
\text { BG/T13625-1992 }\end{array}$ \\
\hline
\end{tabular}

The final test results all met the acceptance criteria, and two samples passed the special test and inspection.

\subsubsection{Commodity survey}

Commodity grade surveys are primarily an assessment of supplier quality management systems and capabilities. By assessing the quality management system of the liquid level transmitter supply company and the operation performance of the liquid level transmitter, check whether the quality management system of the liquid level transmitter supply company meets the requirements of HAF003 and RCC-E. Among them, the quality management system includes the work performance, personnel qualifications, workplace, facilities and equipment, management system, quality assurance system and quality assurance program, confirming that the supplier's quality control system is in a controllable state. The quality management system of this batch of equipment manufacturers has obtained ISO9001 system certification, and as a sub-supplier of many nuclear power plant emergency diesel generator suppliers in my country, it has relatively mature manufacturing experience and good supply performance. Therefore, the company's quality management system is basically effective, and its quality management capabilities are acceptable.

\subsubsection{Quality record check}

The quality record is primarily an assessment of the quality of the entire batch of purchased equipment. Since certain tests and inspections only select some equipment for testing, and some tests are destructive, it can only prove that the performance of this type of equipment meets the procurement requirements. A commodity-level survey can only prove that the equipment supplier has the quality management capability to meet the corresponding regulatory requirements. For suppliers that do not have a nuclear warranty system, the quality record of the batch of equipment must be checked to determine that the supplier's production process for the batch is in a quality-controlled state. This CGD quality record inspection includes product user manuals, product technical specifications, manufacturing completion reports, factory test records and reports, product qualification certificates, packing lists and other documents. The supplier has established the quality assurance program and procedures comprehensive quality record file system.

\subsection{Implementation of acceptance activities}

Acceptance activities are carried out in accordance with established acceptance methods and standards. The organization that intends to carry out the evaluation of commercial grade items must establish a nuclear quality assurance system that meets the requirements of HAF003, including equipment purchasers, nuclear power plant operating units, nuclear-grade complete equipment suppliers and third-party institutions that meet the requirements. The equipment purchased are all of the same model. Two samples are used for special tests and inspections, some are installed and used, and some are used as spare parts. For this batch of equipment, the purchaser has verified the quality of all equipment to varying degrees. The purchaser selected 2 samples for special tests and inspections, and the results were qualified. At the same time, the purchaser has carried out the delivery acceptance of other liquid level transmitters. The test items include visual inspection and functional performance verification (after each level gauge has been calibrated for low and high positions, three liquid level depth values are selected for accuracy test verification) and the change of the level gauge output signal with the level, each level gauge meets the 1\% (and all less than 3 $\mathrm{mm}$ ) measurement accuracy requirements, and all test items are qualified.

\subsection{Record of acceptance activity results}

The purchaser recorded the results of the entire acceptance process and formed an acceptance report. The report includes the equipment acceptance process, acceptance conclusion and acceptance test record, and the equipment and document information have corresponding traceability.

\section{Conclusion}

The evaluation of commercial grade items is more common in the US nuclear industry, and it is an effective means to improve the procurement management and acceptance of items such as complete sets of equipment parts and bulk materials. With the large number of nuclear power plants entering China's commercial operation 
phase, the number of spare parts purchased has increased year by year. In China, the evaluation of commercial grade items can improve the nuclear equipment supervision system and means, and implement the supplier's responsibility, thereby improving the quality of nuclear equipment control level. Taking the liquid level transmitter of emergency diesel generator set as an example, this paper analyzes the document system, work flow and key characteristics of the equipment-level item evaluation, and hopes to provide certain for the development of commercial grade items in the industry.

\section{References}

1. IEEE STD-323-2003. Standard for Qualifying Class 1E Equipment for Nuclear Power Generating Stations[R]. IEEE, 2003.
2. Criteria for Use of Computers in Safety Systems of Nuclear Power Plants. RG1.152 . 2011

3. Guideline for Sampling in the Commercial-Grade Item Acceptance Process. EPRI TR-017218-R1 . 1999

4. Guideline for the acceptance of commercial-grade items in nuclear safety-related applications. EPRI. EPRI TR-3002002982 . 2014

5. EPRI NP-5652, Guideline for the Utilization of Commercial Grade Items In Nuclear Safety Related Applications, Electric Power Research Institute[R]. Electric Power Research Institute, 1988.

6. EPRI TR-102260. Supplemental Guidance for the Application of EPRI Report NP-5652 on the Utilization of Commercial Grade Items[R]. Electric Power Research Institute, 1994. 